\title{
Review: Adducts and Clusters in Chromatography, Mass Spectrometry and Nature
}

\author{
Ilia Brondz \\ Norwegian Drug Control and Drug Discovery Institute (NDCDDI) AS, Ski, Norway \\ Email: ilia.brondz@gmail.com
}

Received 2 June 2016; accepted 26 June 2016; published 29 June 2016

Copyright (C) 2016 by author and Scientific Research Publishing Inc.

This work is licensed under the Creative Commons Attribution International License (CC BY).

http://creativecommons.org/licenses/by/4.0/

(c) (i) Open Access

\begin{abstract}
The word "clusters" in scientific terminology as aggregated molecules or atoms appeared in chemistry relatively recently. The terms clusters have been used intensively since the discovery of fullerenes. The term cluster is not a new one for other branches of science such as astrophysics-star cluster, globular cluster, galaxy cluster, in biology and medicine-cancer cluster, genetic cluster, or in computing-data cluster. Adducts in chemistry were known significantly earlier. Both clusters and adducts are assemblies of atoms or molecules that are held together by weak van der Waals or London dispersion forces. Clusters are homogeneous and usually consist of one sort of atom or molecule. Clusters can also be a host for other types of atoms or molecules. Adducts usually consist of two different types of molecules, one of which is the host molecule. Both clusters and adducts are well defined by IUPAC. The present short review describes some important phenomena of these intriguing associations, which have interest for chemical extraction, separation, analysis, and for nature in general.
\end{abstract}

\section{Keywords}

Clusters, Adducts, Chromatography, Mass Spectrometry, Icosahedral Structures

\section{Introduction}

\section{Clusters in Sub- and Supercritical Fluids}

William C. Swope et al., already in 1982 described in paper A computer simulation method for the calculation of equilibrium constants for the formation of physical clusters of molecules: Application to small water clusters [1] the calculation method which is based on Hill's formal theory for the formation of clusters of two to five water 
molecules. In new book Discovering the Cluster World published by B. Sedunov [2], he shows how precise electronic databases may be used to discover unknown properties of equilibrium clusters. He describes original methods to extract the hidden knowledge from precise experimental data.

This knowledge can be useful for optimizing High Performance Liquid Chromatography (HPLC), Supercritical Fluid Chromatography (SFC), Supercritical Fluid Extraction (SFE) and all kind of extractions by liquids in which clusters are present. The mass-transference between liquid and stationary phase under chromatograph process plays a crucial role in compactness of chromatography bonds, separation power, speed of analysis, minimal detection concentration and several other important parameters. Acceptance in chromatography of the existence of clusters in the system as liquid phase-clusters in the liquid phase and a liquid phase of bonded phaseclusters, has led to the mass-transfer process looking more complicated than when it was traditionally accepted as mass transfer between the liquid and stationary phases (solid/bonded phase). There is the third factor which can take place in the equation-it is clusters. Solubility of analyte in clusters is different from this in liquid. The solubility of analyte in presence of clusters in mobile phase is different from solubility of analyte in liquid mobile phase if clusters were absent in liquid. In liquid mobile phase can be present several types of clusters as 1D, 2D and 3D. The clusters can be from bimolecular to multi-molecular aggregates. Under isocratic elution it has been expected stable situation for clusters, because the concentration of analyte in mobile phase is minimal, stable under process and all parameters in the process are stable. However, under gradient elution the situation for clusters depends dynamically from changes of elution's parameters. Instead of binary situation which is an isocratic elution when mass-transference between liquid and stationary phase was dominated for theoretical description of chromatographic separation process, the triple phases (mass-transference between liquid phaseclusters, stationary phase-clusters and cluster phase-analyte) should be taken in account. By gradient elution the situation is more complex because of dynamic factors in process. It is difficult to calculate theoretically at the present time by the present knowledge; we possess the real mass-transference because we do not know the solubility of analyte in the clusters, concentration and type of clusters in mobile phase. Approximations are not good enough in some cases.

A long time ago, it was discovered that liquid water consists of liquid phase and clusters of $\left(\mathrm{H}_{2} \mathrm{O}\right)_{2}$ or $\left(\mathrm{H}_{2} \mathrm{O}\right)_{n}$ molecules [3]-[6]. A fullerene-like cluster for water, $\left(\mathrm{H}_{2} \mathrm{O}\right)_{28}$ has been predicted. There exists water molecule monster icosahedral network [7]. The existence of 280 molecules icosahedral structure with 20, 60, 100 and 280 shells which is $3 \mathrm{~nm}$ in diameter was confirmed. The shells show the increased stability by addition of each shell [8]. The reviews about the water molecule clusters are presented in [9] [10]. The particle size usually used by stationary phase in column for HPLC and SFC vary from $5 \mu$ to $3 \mu$ and the pore diameter in particles of stationary phase vary from $300 \AA$ to $120 \AA$. One $\mu$ is a one micron, in the SI system derived unit of length equaling 1 $\times 10^{-6}$ of a meter. One angstroms $\AA$ is equaling $1 \times 10^{-10}$ of a meter. One nanometer equals ten angstroms. It means that icosahedral cluster with 280 shells which is $3 \mathrm{~nm}$ in diameter (which is $30 \AA$ in diameter) can freely enter the pores in stationary (or bonded phase), interact with analyte molecules and leave the pores of stationary phase to the liquid phase or (vice versa) and after this exchange by mass transport between the clusters and liquid or between the cluster with clathrated analyte molecule and stationary phase. Situation with presence of host-guest complexes and inclusion compounds have been described in [11]. Clusters in mobile phase and in pores of stationary phase can have significant influence on chromatography process by overall mass transference process. The host-guest complexes and inclusion compounds can be stable and were used for isolation of pure substances [12]. Chromatography or extraction process will strong depend on partition coefficient of analyte for the systems: liquid-analyte clathrate in cluster and stationary phase-analyte clathrate in cluster. The same situation as in water is correct also for organic liquids, water-organic mixtures, ionic-, sub- and supercritical fluid phases and even in dense gases. Water as a pure liquid phase with addition of low concentration of inorganic ions was nearly neglected in HPLC or very seldom used. Besides of ion exchange chromatography or electrophoresis it is difficult to find references to use of water as a pure liquid phase for HPLC. However, the successful use of water as liquid phase by HPLC was demonstrated in [13]-[16].

\section{The Role of Clusters in Chromatography}

The knowledge about situation in clusters as host-guest complexes and analyte inclusion compounds with clusters is important for optimization of HPLC, SFC and all kind of extractions with fluids in normal stage and supercritical fluid technologies as SFC and SFE. The theoretical aspects of separation to individual substances 
from the complex mixtures by using chromatography columns in capillary columns supercritical fluid chromatography (CCSFC) and packed columns supercritical fluid chromatography (PCSFP) are not sufficiently based up to present time. Especially it is a situation in the PCSFC where the maintenance of supercritical $\mathrm{CO}_{2}$ or other supercritical phase in packed column in the supercritical state is regulated by three important parameters. The parameters are: temperature, pressure and the molar concentration of the modifier. The concentration of modifier can be zero. In this case there are two parameters which govern the process. The parameters for $\mathrm{CO}_{2}$ have been presented on the triple point diagram Figure 1, and they are governing the separation of substances in complex mixture under SFC process. The appearance of $\mathrm{CO}_{2}$ molecules (and $\left(\mathrm{CO}_{2}\right)_{\mathrm{n}}$ molecules with analyte under analysis) as clusters in the case could be predicted from the diagram in Figure 1, because the concentration of analyte in the system is negligibly small. However, the solubility of analyte in clusters is unknown. The more complicated situation is in the case of a presence of modifier, because the concentration of modifier can be significant and the modifier can be by itself a complex mixture of substances. The theoretical background in the case is poorly described or absent. The $\mathrm{CO}_{2}$ is a common supercritical fluid for SFC.

However, the other supercritical fluids including overheated water have been used in laboratories of Norwegian Drug Control and Drug Discovery Institute (NDCDDI) AS, Norway. The supercritical properties of substances are presented in Table 1.

The water dumps were used for centuries for extraction, the overheated water also can be used as supercritical fluid for SFE and SFC.

The theoretical background for supporting the practical work in chromatography including presence of clusters in these substances, which had been named in Table 1 , is absent. The $\mathrm{CO}_{2}$ is a strong lipophilic dry phase and it is not polar. Sometime, there is technical need to use other lipophilic phases as $n$-butane or $\mathrm{F}_{6} \mathrm{~S}$ or more polar phases as $\mathrm{NH}_{3}$ or $\mathrm{N}_{2} \mathrm{O}$.

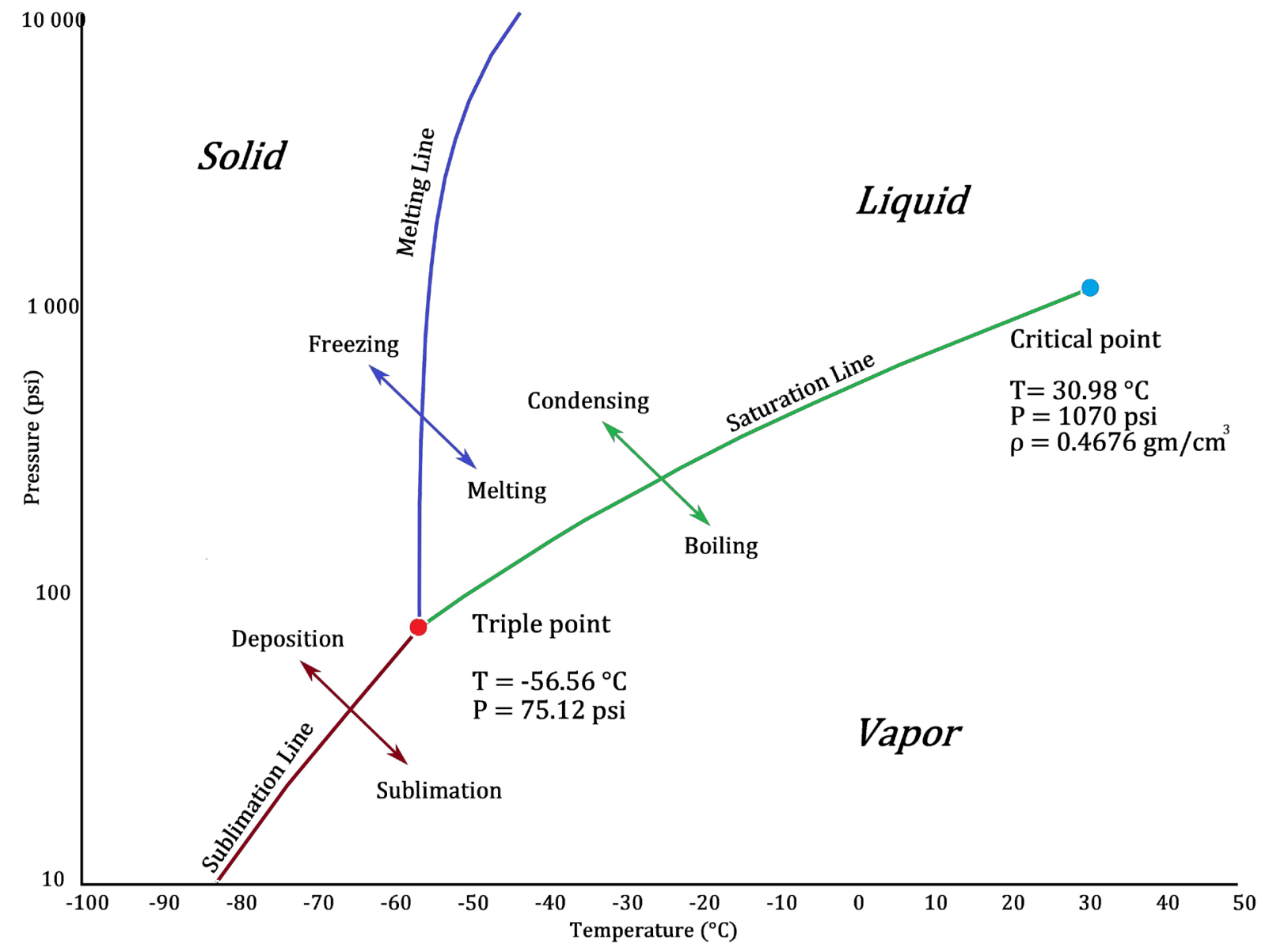

Figure 1. The triple and critical points diagram for $\mathrm{CO}_{2}$. 
Table 1. The supercritical properties of substances used in SFC.

\begin{tabular}{cccc}
\hline Substance & Critical Temperature & Critical Point Density & Critical Pressure \\
\hline & ${ }^{\circ} \mathrm{C}$ & $\mathrm{g} / \mathrm{mL}$ & $\mathrm{atm}$ \\
$\mathrm{CO}_{2}$ & 31.3 & 0.47 & 72.9 \\
$\mathrm{~N}_{2} \mathrm{O}$ & 36.5 & 0.45 & 71.7 \\
$\mathrm{~F}_{6} \mathrm{~S}$ & 45.6 & 0.74 & 37.1 \\
$\mathrm{NH}_{3}$ & 132.5 & 0.24 & 112.5 \\
$n$-butane & 152.0 & 0.23 & 37.5 \\
$\mathrm{H}_{2} \mathrm{O}$ & 374 & 0.32 & 217.7 \\
\hline
\end{tabular}

The parameters during isocratic SFC are stable and operator controls them. However, the pressure along the column's length decreases from the inlet to the outlet, despite the presence of back-pressure regulator (BPR). In the case of gradient chromatography, there is a dynamic change of gradients as: modifier, pressure or temperature; or all of them. In this case all parameters: temperature, concentration of modifier in supercritical fluid and pressure are dynamically connected and they have influence on stability, concentration, type of clusters and solubility of analyte in clusters as overall mass transference process. Despite the presence of BPR the supercritical state of mobile phase never can be achieved in the whole length of a column. The supercritical state of mobile phase can be achieved only in parts of a column. The usual and best operation scenario is the presence of a liquid phase in the head of a column and a supercritical fluid phase in the rest of the column and may be in the detector. The separation of chromatographic bonds in the column strongly depends on mass-transference between mobile phase and stationary phase and by pattern of flow in chromatographic column as the length correlation of the liquid fraction to the supercritical fraction in a column. It can also strongly depend from cluster dynamic in the process in whole column as well as in different parts of a column. Optimal condition of separation in the process can be achieved only by good knowledge about dynamic, nature and concentration of clusters in mobile liquid and supercritical phase. Because the theoretical description of this is absent up to the present time most of optimizing of chromatographic separation and extraction with supercritical fluids had been achieved by practical experimentation or approximations to the existing theories [17]-[19], the same is truth in parts for HPLC. All attempts in direction to establish theoretical background for chromatography and extraction by taking to consideration host-guest complexes and inclusion compounds of analyte by clusters in liquids is of great importance as development of new theoretical approach to clusters in gas, dense gasses, supercritical fluids, overheated fluids, fluids at standard stage and overheated fluids.

\section{Adducts or Clusters in Mass Spectrometry}

In cases of mass spectrometry interpretation in which the molecular mass ion of substance is not known or may be absent, or exists suspicion about correctness of $\mathrm{M}^{+}$value to mass ion, the use of adducts and cluster molecules for verification of molecular mass ion of the substance can be helpful. Multiple illustrations and examples, based on real experimental data, are informative and useful to professionals and students. The mass spectrum of Pholcodine, Pholcodine-N-oxide and 10-hydroxy-pholcodine with molecular mass 398, 414 and 414 can be supported in mass spectra by molecular mass ions though the use of adducts [20] with H, Na and K, Figure 2. The existence of different species with molecular mass 414 also has been supported by presence of $\mathrm{K}$ adducts. Especially it is important in elucidation case concerning presence of unknown substance in substrate (drug, natural product, clinical and forensic investigation or under experimental synthesis). It is also important for decision about presence of unrecorded before mass number isomers under degradation of substrate [20]. There are two substances appearing as oxidation products of a drug Pholcodine [20]. It is not always the mass molecular ion can be recorded in Mass Spectrum. The additional support about existence of correct recorded molecular mass ion can be gained [20] from presence of adducts. Adducts have been defined by The IUPAC in [21] or from presence of clusters as it has been defined by The IUPAC in [22]. The new IUPAC definition of clusters in Mass Spectrometry is: "An ion formed by the combination of more ions or atoms or molecules of a chemical species often in association with a second species. For example, $\left[\left(\mathrm{H}_{2} \mathrm{O}\right)_{n} \mathrm{H}\right]^{+}$is a cluster ion" [22] gives basis to

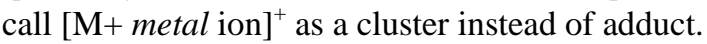



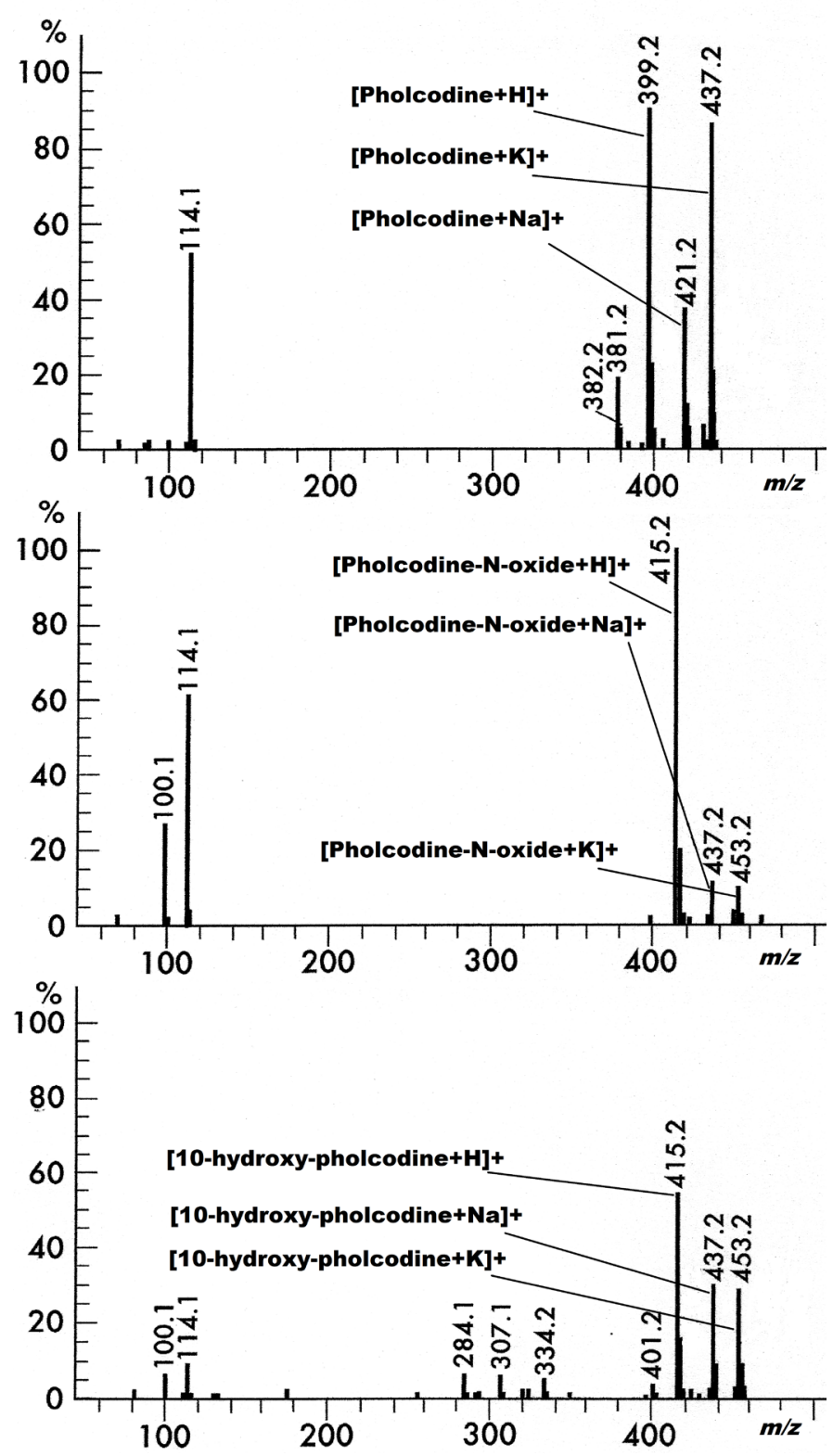

Figure 2. The adducts by definition of [21] or clusters by definition of [22] of $\mathrm{H}$, $\mathrm{Na}$ and $\mathrm{K}$ with pholcodine, pholcodine-N-oxide and 10 hydroxy-pholcodine [20].

In ultrasonic beams of He with addition of small organic molecules has been observed creation of cluster molecules. Rapid expansion of gas in ultrasonic beams as $\mathbf{H e}$ added small organic molecules creates state of super cooling and loosing of kinetic energy. The clusters have been recorded by MS with supersonic molecular beams (MS with SMB). Clusters can be easily demonstrated during chromatography process GC-MS with SMB by addition to mobile gas phase $\mathbf{H e}$ the modifier like methanol ( $\mathrm{MeOH})$ (unpublished results).

\section{The New Approach to Clusters in Nature and Technology}

In Nature many phenomena can be explained by presence in air, water and other liquids or solids of the fine structures as the clusters of molecules. Concentration and size of clusters depend on conditions present in the surrounding phase. In 1899 first time was expressed idea about artificially rain induced precipitation. The first 
record about artificial precipitation of rain was in 1931 from the Netherlands [23]. This was achieved by introduction into the cloud substances in a dispersed state. Substances were named as ice-forming agents. In natural super-cooled cloud, they gave additional centers of condensation in contact with moisture and precipitated as rain. Possibly the precipitated of rain by creating additional centers of condensation were the increased concentration of water clusters and increased size of these clusters. The living cells' protoplasm is a complex mixture of semisolid water consisting gel. In this gel water cluster molecules play significant functions, one of most important of them is ageing of gel by losing of clusters their aggregation structure and becoming as non-structured liquid. There are solid gels also, one of them is pearls. The fine dispersed water-calcium carbonate gel rich with clusters gives to pearls their beautiful half transparent glance. Destruction of this by dryness can transfer the beauty to chalklike substance.

\section{Conclusion}

The theoretical background of clusters' behavior in different systems including the life organisms is in juvenile phase; however, it is important, fruitful and very needed for understanding the subject. We consist and live in world of water clusters; our existence can be significantly improved by understanding of this world. Water clusters regulate ageing of gel in our cells, speed of chemical reactions in organelles, speed of nerve signals and many other phenomena. In technical perspectives understanding of clusters nature and existence (behavior) is important for extraction, chromatography and soil structuration, for many different materials and goods preparation. It is difficult to name the subject which occupies a broader spectrum of theoretical and practical applications than clusters and adducts.

\section{References}

[1] Swope, W.C., Hans, C., Andersen, H.C., Berens, P.H. and Wilson, K.R. (1982) A Computer Simulation Method for the Calculation of Equilibrium Constants for the Formation of Physical Clusters of Molecules: Application to Small Water Clusters. Journal of Chemical Physics, 76, 637-649. http://dx.doi.org/10.1063/1.442716

[2] Sedunov, B. (2015) Discovering the Cluster World. LAP Lambert Academic Publishing, Germany.

[3] Ludwig, R. (2001) Water: From Clusters to the Bulk. Angewandte Chemie International Edition, 40, 1808-1827. http://dx.doi.org/10.1002/1521-3773(20010518)40:10<1808::AID-ANIE1808>3.0.CO;2-1

[4] Fowler, P.W., Quinn, C.M. and Redmond, D.B. (1991) Decorated Fullerenes and Model Structures for Water Clusters. The Journal of Chemical Physics, 95, 7678. http://dx.doi.org/10.1063/1.461341

[5] Ignatov, I. and Mosin, O.V. (2013) Structural Mathematical Models Describing Water Clusters. Journal of Mathematical Theory and Modeling, 3, 72-87.

[6] Keutsch, F.N. and Saykally, R.J. (2001) Water Clusters: Untangling the Mysteries of the Liquid, One Molecule at a Time. PNAS, 98, 10533-10540. http://dx.doi.org/10.1073/pnas.191266498

[7] Sykes, M. (2007) Simulations of RNA Base Pairs in a Nanodroplet Reveal Solvation-Dependent Stability. PNAS, 104, 12336-12340. http://dx.doi.org/10.1073/pnas.0705573104

[8] Loboda, O. and Goncharuk, V. (2010) Theoretical Study on Icosahedral Water Clusters. Chemical Physics Letters, 484, 144-147. http://dx.doi.org/10.1016/j.cplett.2009.11.025

[9] Maheshwary, S., Patel, N., Sathyamurthy, N., Kulkarni, A.D. and Gadre, S.R. (2001) Structure and Stability of Water Clusters $\left(\mathrm{H}_{2} \mathrm{O}\right)_{n}, \mathrm{n}=8$ - 20: An ab initio Investigation. The Journal of Physical Chemistry, 105, 10525-10537. http://dx.doi.org/10.1021/jp013141b

[10] Fanourgakis, G.S., Aprà, E., de Jong, W.A. and Xantheas, S.S. (2005) High-Level ab initio Calculations for the Four Low-Lying Families of Minima of $\left(\mathrm{H}_{2} \mathrm{O}\right)_{20}$. II. Spectroscopic Signatures of the Dodecahedron, Fused Cubes, FaceSharinbucky Water g Pentagonal Prisms, and Edge-Sharing Pentagonal Prisms Hydrogen Bonding Networks. Journal of Chemical Physics, 122, 134304. http://dx.doi.org/10.1063/1.1864892

[11] http://goldbook.iupac.org/C01097.html

[12] Brondz, I. (1979) Antibiotikumet "Hyperforin” og andre innholdsstoffer i drogen Hypricum perforatum L. Thesis, University of Oslo, Oslo Norway. (In Norwegian)

[13] Brondz, I., Hamdani, E.H. and Døving, K. (2004) Neurophysiologic Detector (NPD)—A Selective and Sensitive Tool in High-Performance Liquid Chromatography. Chromatography B: Biomedical Sciences and Applications, 800, 41-47. http://dx.doi.org/10.1016/j.jchromb.2003.07.004

[14] Brondz, I., Hamdani, E.H. and Døving, K. (2004) The Fish Olfactory System Used as an In-Line HPLC Biosensor for 
Analytical Work. International Scientific-Technical Conference "Sensors Electronics and Microsystems Technology (SEMST-1)", Odessa, 1-5 June 2004, 17.

[15] Brondz, I., Hamdani, E.H. and Døving, K. (2004) Isolation of a Fraction Inducing Activity in Neurons of "Alarm Centre” in the Olfactory Bulb of the Crucian Carp, Carassiuscarassius L. The European Chemoreception Research Organisation ECRO 2004 Congress, Dijon, 12-15 September 2004, 3.

[16] Brondz, I. (2015) High-Performance Liquid Chromatograph (HPLC) Equipped with a Neurophysiological Detector (NPD) as a Tool for Studying Olfactory System Intoxication by the Organophosphate (OP) Pesticide Diazinon and the Influence of OP Pesticides on Reproduction. International Journal of Analytical Mass Spectrometry and Chromatography, 3, 14-24. http://dx.doi.org/10.4236/ijamsc.2015.31002

[17] Einstein, A. (1905) Über die von der molekularkinetischen Theorie der Wärme geforderte Bewegung von in ruhenden Flüssigkeiten suspendierten Teilchen. Annalen der Physik (In German), 322, 549-560. http://dx.doi.org/10.1002/andp.19053220806

[18] Sutherland, W. (1905) A Dynamical Theory of Diffusion for Non-Electrolytes and the Molecular Mass of Albumin. Philosophical Magazine Series 6, 9, 781-785. http://dx.doi.org/10.1080/14786440509463331

[19] Von Smoluchowski, M. (1906) Zur kinetischen Theorie der Brownschen Molekularbewegung und der Suspensionen. Annalen der Physik (In German), 326, 756-780. http://dx.doi.org/10.1002/andp.19063261405

[20] Brondz, I. (2013) Mass Spectrometric Structure Elucidation of the Trivalent and Pentavalent Nitrogen Contaminants of Pholcodine in Cough Relief Medical Form Tuxidrin. International Journal of Analytical Mass Spectrometry and Chromatography, 1, 5-10. http://dx.doi.org/10.4236/ijamsc.2013.11002

[21] IUPAC (1997) Compendium of Chemical Terminology-The "Gold Book". 2nd Edition, McNaught, A.D. and Wilkinson, A., Compiled, Blackwell Scientific Publications, Oxford. (2006-) Created by Nic, M., Jirat, J. and Kosata, B., Updates Compiled by Jenkins, A. http://goldbook.iupac.org

[22] IUPAC (1997) Compendium of Chemical Terminology—-The "Gold Book". 2nd Edition, McNaught, A.D. and Wilkinson, A., Compiled, Blackwell Scientific Publications, Oxford. (2006-) Created by Nic, M., Jirat, J. and Kosata, B., Updates Compiled by Jenkins, A. http://www.iupac.org/goldbook/C01115.pdf

[23] Kachurin, L.G. (1990) Physical Basis of Impact on Atmospheric Processes. Gidrometeoizdat, Leningrad, 464.

\section{Submit or recommend next manuscript to SCIRP and we will provide best service for you:}

Accepting pre-submission inquiries through Email, Facebook, Linkedin, Twitter, etc

A wide selection of journals (inclusive of 9 subjects, more than 200 journals)

Providing a 24-hour high-quality service

User-friendly online submission system

Fair and swift peer-review system

Efficient typesetting and proofreading procedure

Display of the result of downloads and visits, as well as the number of cited articles

Maximum dissemination of your research work

Submit your manuscript at: http://papersubmission.scirp.org/ 